\title{
IMPACT OF LOW COST AIRLINES ON UPPER CLASS RAIL TRANSPORT FOR LONG-HAUL TRAVEL IN INDIA
}

\author{
Nivetha Nithiyanandam ${ }^{1}$, Sivaranjani Rajakamangalam Sivathanupillai ${ }^{2}$, Sivasankari \\ Rajendran ${ }^{3}$, Sree Swathi Jayasankar ${ }^{4}$, Selvakumar Muthusamy ${ }^{5}$ \\ 1,2,3,4,5 Department of Civil Engineering, Sri Venkateswara College of Engineering (SVCE), \\ Sriperumbudur, India
}

Received 19 June 2019; accepted 29 December 2019

\begin{abstract}
Modal shift arises when a new mode (or upgraded mode) has an added advantage(s) over the existing mode for the same cost of travel. Present study aims to examine the shift behaviour of upper class rail passengers (AC - First Class, I-AC \& AC - 2 Tier, II-AC) to Low Cost Airlines (LCA) under long-haul scenario (distance $>1,000 \mathrm{Km}$ ) in India. For this purpose, a Stated Preference (SP) questionnaire was prepared and conducted face-to-face interview survey among 300 upper class rail passengers whose trip origin as Chennai (India). The survey data was coded and a binary Logit model was developed using Statistical Software Tools (SST) software. The results indicated that the passengers making personal trip with age more than sixty travelling in upper class rail are more likely to switch to LCA. Whereas passengers who think the air travel is costly are less likely to switch to air mode. Proposed fare difference significantly influenced in modal shift behaviour with $\mathrm{t}$-value of -18.46 . The study revealed that when the air fare is equal to I AC class rail fare, $95 \%$ of upper class passengers are willing to shift to air mode.
\end{abstract}

Keywords: modal shift, railways, Logit model, low cost airlines, India.

\section{Introduction}

India has fourth largest rail network in the world next to Russia with 67,312 kilometres $(41,826$ miles) of route length running across breadth and width of the country. In India, railway is owned and operated by Indian Railways (IR) which is one of the largest monopolies in the world till today. Whereas air transport was only operated by the government owned carriers Air India and Indian Airlines (domestic) till the mid of 1990s. 'Open Sky Policy' was introduced in the year 1994; subsequently private airlines were permitted to operate air services under the control of Director General of Civil Aviation (DGCA). Till the year 2000, few private airlines operated services and subsequently withdrawn their operations. There was not much intermodal competition during above period (i.e. 19942000). However, after the year 2000 , many private operators entered the market, and the stiff competition among carriers' resulted in reduction of airfare to attract passengers, which is almost close to I AC rail fare (Table 1). Similarly in 2018, Indian Railways introduced flexi fare system (dynamic fare) for major long-haul routes resulted in vibrant intermodal competition.

\footnotetext{
${ }^{5}$ Corresponding author: msk@svce.ac.in
} 
Table 1

Comparison of Fare for I-AC Rail and LCA for Long-Haul Travel

\begin{tabular}{|c|c|c|c|}
\hline S. No. & Parameter for Rail & Rail & \multicolumn{2}{c|}{ Air } \\
\hline 1. & Origin - Destination & \multicolumn{2}{|c|}{ Chennai - New Delhi } \\
\hline 2. & Category of Transport & Superfast Train & LCA \\
\hline 3. & Class & I AC & Economy \\
\hline 4. & Travel time (hr-min) & $33-05$ & 55 \\
\hline 5. & Travel cost (Fare, Rs (in $€))$ & $5,190(65.71)$ & $5,551(70.28)$ \\
\hline
\end{tabular}

Source: Indian Railways \& Google Flights (Feb 2019)

Hence there may be potential shift of upper class rail passengers to LCA to reap the benefit of travel time saving for long-haul scenario. To understand the influence of LCA on upper class rail, a SP questionnaire was prepared and conducted face-to-face interview survey among I AC \& II AC rail passengers for the stated 4 hypothetical air fare scenarios:

- Scenario 1: When the air fare is equal to I AC rail fare;

- Scenario 2: When the air fare is $10 \%$ higher than the I AC rail fare;

- Scenario 3: When the air fare is $20 \%$ higher than the I AC rail fare;

- Scenario 4: When the air fare is $30 \%$ higher than the I AC rail fare.

A binary Logit model was developed using the above data to calculate the probability of shift. Estimated probability indicated that when the LCA fare is equal to I AC rail fare (scenario 1) the probability of shift expected is $95 \%$ and when the LCA fare is $30 \%$ higher than the I AC rail fare (scenario 4) the probability of shift drastically reduced to $3 \%$. This shows that the upper class rail passengers are highly price sensitive for LCA fare.

\section{Literature Review}

Literature review is necessary for understanding the basic idea on model building exercise. Few studies conducted in developed countries as well as developing countries were presented here.

(Morikawa et al., 1991) have developed a methodology for incorporation of Revealed Preference (RP) and SP data in discrete choice model for intercity mode choice analysis. Three models were estimated: RP model, SP model, and combined RP/SP model. The factors influencing in the mode choice were line haul travel time, access \& egress time, travel cost and business trip dummy variable.

Attitudes towards intercity bus travel in Texas have been studied by (Fitzpatrick et al., 1996) to understand the intercity bus needs. To accomplish this objective, surveys were developed and distributed towards the general population, bus riders and bus companies in the state. General-population respondents indicated that they would be more likely to ride a bus if there were more express bus service, better station locations, and higher air and train fares. Bus riders indicated they would ride more often if there were improved security measures at stations and on buses, more leg room, more comfortable seats, adherence to schedules, and lower bus fares.

In a binary Logit analysis with unequal sample frequencies of the two outcomes 
the less frequent outcome always has lower estimated prediction probabilities than the other outcome was found by (Cramer, 1999). This effect is unavoidable, and its extent varies inversely with the fit of the model unbalanced samples with a poor fit are typical for survey analyses in the social sciences and epidemiology, and there the difference in prediction probabilities is most acute. Partial remedies are suggested.

(Sivakumar et al., 2006) conducted a survey on BRT implementation with SP as a hypothetical tool at a selected corridor in Colombo, the capital of Sri Lanka. In this survey design, system explanation has been set in two slightly different ways for comparison and it was found that even a slight difference on design affected the users' response considerably.

(Hunt et al., 2007) have done a study to identify factors on bicycle use at Canada. A SP experiment was performed in Edmonton in Canada to both examine the nature of various influences on bicycle use. The results indicate, among other things, that time spent cycling in mixed traffic is more onerous than time spent cycling on bike lanes or bike paths; that secure parking is more important than showers at the destination.

Road safety impact of a modal shift from short car trips to cycling in Dutch municipalities was studied by (Schepers et al., 2013). The road safety effect is estimated using Accident Prediction Models (APMs) that account for the non-linearity of risk. APMs are developed utilizing Negative Binomial regression. This study is the first to develop APMs using crash and mobility data from municipalities, and utilizing these models to estimate the effects of changing modal splits of current car and bicycle use to modal splits that actually exist in these municipalities. The results suggest that, under conditions such as in Dutch municipalities, transferring short trips made by cars to bicycles does not change the number of fatalities, but increases the number of serious road injuries.

Impact of high-speed rail on domestic air transportation in China was studied by Chen (2017) using a new comprehensive modelling framework utilizing both supply and demand perspectives. Assessment was conducted using an improved panel regression model by taking into account of the detailed opening schedules of various HSR services during the period 2001-2014. The research findings reveal that the deployed HSR services have a significant substitutional effect on domestic air transportation in China, but the effect varies across different HSR routes, travel distance and city type.

(Li et al., 2018) studied the effect of highspeed rail on air passenger transport in China. The difference-in-differences approach was used with unbalanced panel data of 206 airports over the period from 2006 to 2015 . The estimated results found that the negative effect of HSR on the growth rate of China's air passengers was both statistically and economically significant. However, these adverse effects were not catastrophic (take long time).

\section{Objectives of the Study}

Following are the main objectives of the study:

1. To prepare SP questionnaire, conduct the survey among upper class rail passengers (I AC \& II AC) those making long-haul trips from Chennai; 
2. To develop a binary Logit model and estimate the probable shift from upper class rail to LCA for stated fare scenarios.

\section{Methodology}

The modal shift model was built using SP data collected through passenger interview survey. Instead of Probit model, Logit model was developed for easy understanding of relationship between dependent variable (Probability of Shift) with other influencing independent socio-economic variables (Akiva). Since, in this study only two modes (rail and air) were involved, binary Logit model is used for predicting probability. The methodology of model development is shown in Fig.1. The shaded area indicates the study methodology.

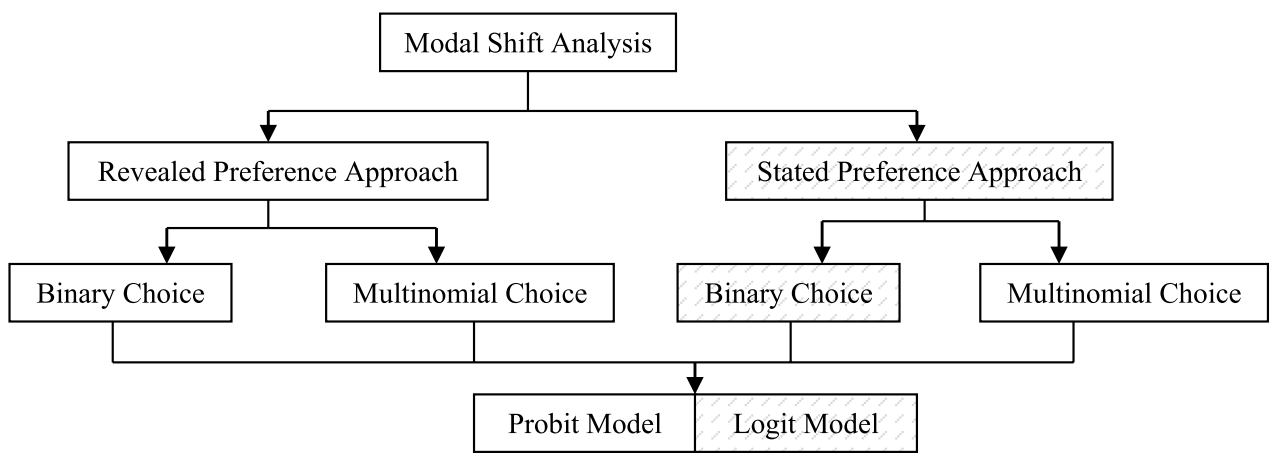

Fig. 1.

Study Methodology

\section{Data Collection}

Assuming that 10 significant variables in the final model and each independent variable requires 30 data points for better correlation with dependent variable (Cohen, 1988), 300 upper class rail passengers $(10 \times 30=300)$ were interviewed by face-to-face method. SP questionnaire was prepared so as to collect require socio-economic and travel characteristics in order to understand the behaviour of upper class rail passengers during Feb 2019. Following information was collected as part of the SP survey:

Table 2

Factors Considered in SP Questionnaire

\begin{tabular}{|c|c|c|c|c|}
\hline $\begin{array}{c}\text { Socio-economic } \\
\text { factors }\end{array}$ & $\begin{array}{c}\text { Trip } \\
\text { Characteristics }\end{array}$ & Opinion on LCA & $\begin{array}{c}\text { Detailed on } \\
\text { last air travel }\end{array}$ & Stated fare scenario \\
\hline $\begin{array}{c}\text { Age; Educational } \\
\text { Qualification; }\end{array}$ & $\begin{array}{c}\text { Origin - Destination; } \\
\text { Purpose of trip; } \\
\text { Employment type; } \\
\text { frequency; fare paid } \\
\text { Occupation; Annual } \\
\text { Income }\end{array}$ & $\begin{array}{c}\text { Safety of air travel; } \\
\text { perception about air } \\
\text { fare; connectivity of } \\
\text { air for the present trip }\end{array}$ & $\begin{array}{c}\text { Origin - Destination; } \\
\text { Purpose of trip; fare } \\
\text { paid (self / company) }\end{array}$ & $\begin{array}{c}\text { Air fare is equal to I } \\
\text { AC rail fare; } 10 \% / \\
20 \% / 30 \% \text { higher } \\
\text { than I AC air fare }\end{array}$ \\
\hline
\end{tabular}




\section{Data Analysis}

Using SP questionnaire survey, required data were collected by face-to-face interview method among upper class rail travellers. Thus collected data was analysed and model shift model was developed using SST software. Statistical Software Tools (SST) was developed by California Institute of Technology, Berkeley. SST is used for regression analysis, Logit modelling and other statistical analysis. The comments are very simple and easy to use.

Coding means the transformation of data into a form understandable by computer software. Binary coding system is used to feed data for the software. Thus the coded data were feed into software and modal shift model was developed. Initially significantly influencing variables were identified by step by-step procedure. Using the major influencing variables, final model was developed.

\section{Model Development}

In order to be able to use a model in a practical situation, it is necessary to estimate

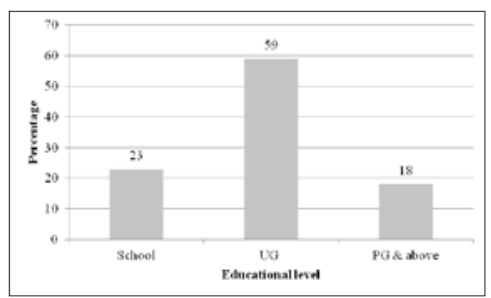

Fig. 2a.

Educational Distribution of Rail Passengers the model parameters from survey data. As the dependent variable is discrete in nature, the model was calibrated by maximum likelihood estimation using Newton Raphson method.

\subsection{Structure of the Model}

Structure of the model is given below (Eq. 1):

$P_{\text {Shift }}=\frac{e^{V_{i}}}{1+e^{V_{i}}}$

where,

$\mathrm{P}_{\text {shift }}=$ probability of shift from one mode to another mode;

$\mathrm{V}_{\mathrm{i}}=$ utility function with an error term ' $\varepsilon$ ';

$V_{i}=\beta_{0}+\beta_{1} x_{1}+\beta_{2} x_{2}+\ldots \ldots \ldots \beta_{n} x_{n}+\varepsilon ;$

$\beta_{0}, \beta_{1}, \beta_{2}, \ldots$ are model parameters to be calibrated;

$\mathrm{x}_{1}, \mathrm{x}_{2}$ are influencing factors in modal shift; $\varepsilon$ is a random error term.

\subsection{Socio-Economic Distribution}

Following are the socio-economic profile of upper class rail passengers observed from the samples collected (Fig. 2).

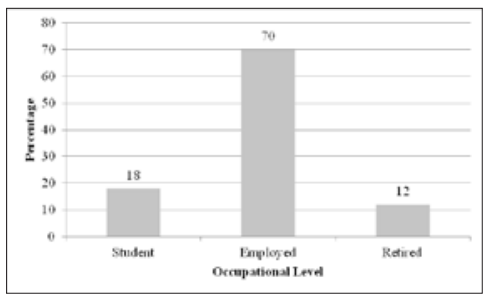

Fig. 2 b.

Occupation Distribution of Rail Passengers 


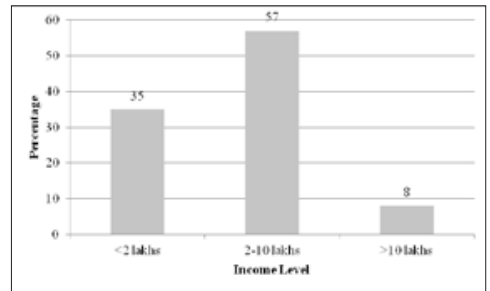

Fig. 2c.

Income Distribution of Rail Passengers

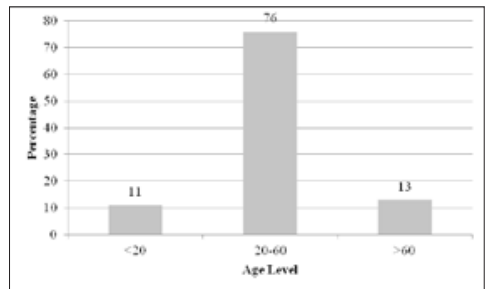

Fig. 2d.

Age Distribution of Rail Passengers

Fig.2

Socio-economic Distribution of Upper Class Rail Passengers

Observations

1. Regarding educational level, $77 \%$ of upper class rail passengers are having qualification above school education;

2. $12-13 \%$ of passengers are retired with age above 60 ;

3. Around $60 \%$ of passengers have an annual income between 2 - 10 lakhs $(\approx 2534-12,671 €)$.

\subsection{Model Calibration}

The total number of data points for model development was 1200 (that is 300 samples with 4 stated hypothetical fare scenarios). Initial model was developed using 920 data points for model validation purpose. Thus developed model (using 920 data points) was applied on remaining 280 data points and log-likelihood values were calculated. The estimated log-likelihood value from the model as well as calculated log-likelihood value were almost matching indicated that the model was valid. Final recalibrated model was developed using all the 1200 data points and results are presented in Table 3.

\section{Table 3}

Results of Recalibration Modal Shift Model

\begin{tabular}{|c|c|c|}
\hline Independent variable & Estimated co-efficient & t-statistics \\
\hline Constant & 2.96 & 10.69 \\
\hline People who are employed & -0.31 & -1.98 \\
\hline People with income more than 10 lakhs $(>12671 €)$ & -0.70 & 1.46 \\
\hline Personal trip & 0.34 & 4.2 \\
\hline People who think air travel is unsafe & 1.06 & -3.80 \\
\hline People who think air travel is very costly & -0.93 & -18.46 \\
\hline People with age greater than 60 & 0.84 & -831.78 \\
\hline Fare difference & -23.08 & -409.32 \\
\hline Initial log-likelihood & \multicolumn{2}{|c|}{0.51} \\
\hline Final log-likelihood & \multicolumn{2}{|c}{} \\
\hline$\rho 2$ & & \\
\hline
\end{tabular}


Observations

1. Fare difference between I AC and air fare is the significant driving force in modal shift in the model (-23.08 with t-stat -18.46). The negative sign indicates that higher the air fare, people are less willing to shift to air (disutility);

2. Passenger with annual income more than 10 lakhs are not willing to shift (-0.70 with t-stat -1.98$)$;

3. Personal trip makers are more willing to shift to LCA (0.34 with t-stat value 0.34 );

4. Passenger who thinks air travel is very costly is less willing to shift (-0.93 with t-stat value -3.80$)$;

5. Passenger with age greater than 60 are more willing to shift to LCA (0.84 with t-stat 2.94);

6. Passenger who are employed are less willing to shift (-0.31 with t-stat 0.21$)$.

\section{Estimation of Probability of Shift}

Based on the modal shift model developed, probability of shift from I and II class AC (Rail) to LCA for different fare levels are calculated and presented in Table 4. It can be observed that the probability of shift is high when fare difference is lower and vice versa. That is, when fare increases, passengers are less willing to shift. Also it can be noted that probability of shift is drastically comes down when the fare increases by $10 \%$ and $20 \%$.

Table 4

Probability of Shift to LCA

\begin{tabular}{|c|c|c|}
\hline S1. No. & Fare Scenario & Probability of Shift to LCA \\
\hline 1 & Air fare is equal to I AC rail & $95 \%$ \\
\hline 2 & Air fare is 10\% more than I AC rail & $68 \%$ \\
\hline 3 & Air fare is $20 \%$ more than I AC rail & $21 \%$ \\
\hline 4 & Air fare is 30\% more than I AC rail & $3 \%$ \\
\hline
\end{tabular}

\section{Conclusions}

A SP approach was used to study the shift of I and II AC (long haul train) passengers to LCA. A binary choice Logit model was developed using SP data to arrive probable shift to LCA. Based on the model development, following conclusions were arrived:

1. Regarding educational level, $77 \%$ of upper class rail passengers are having qualification above school education;

2. $12-13 \%$ of passengers are retired with age above 60 ;

3. Fare difference was the significant driving force in modal shift in the model. The negative sign indicated that higher the air fare, people were less willing to shift to LCA (disutility);

4. Passenger with annual income more than 10 lakhs $(\approx 12671 €)$ were not willing to shift;

5. I and II AC passengers those who were feeling air fare was high were not willing to shift;

6. I and II AC Passengers with age group greater than 60 were willing to shift to LCA;

7. Estimated probability of shift indicated that when LCA fare was equal I AC the probability of shift was $95 \%$ and when the LCA fare was $30 \%$ more than I class AC then the probability of shift was $3 \%$. This showed that the upper class rail travelers were "highly price sensitive". 


\section{Acknowledgement}

Authors are indebted to Sri Venkateswara College of Engineering (SVCE), Sriperumbudur for supporting our project work and providing us all the necessary facilities.

\section{References}

Akiva, M.E.; Lerman, S.R. 1989. Discrete Choice Analysis: Theory and Application to Travel Demand, MIT Press. 390 p.

Chen, Z. 2017. Impact of high-speed rail on domestic air transportation in China, Journal of Transport Geography 62: 184-196.

Cohen, J. 1988. Statistical Power Analysis for the Behavioural Sciences, 2nd edn. Lawrence Erlbaum Associates, New York. 579 p.

Fitzpatrick, K.; Kuenzer, K.; Lienau, T. 1996. Attitudes towards intercity bus travel in Texas, Transportation Research Record: Journal of the Transportation Research Board 1557(1): 64-71.

Google Flights. 2019. Flights. Available from Internet: <https://www.google.com/flights? >. [Accessed on 09 Feb 2019].

Hunt, J.D.; Abraham, J.E. 2007. Influences on bicycle use, Transportation 34(4): 453-470.
Indian Railways. 2019. Indian Railways Passenger Reservation Enquiry. Available from Internet <http:// www.indianrail.gov.in/enquiry/FARE/FareEnquiry. html?locale $=e n>$. [Accessed on $09 \mathrm{Feb} 2019$ ].

Cramer, J.S. 1999. Predictive performance of the binary Logit model in unbalanced samples, Journal of the Royal Statistical Society: Series D (The Statistician) Banner 48(1): 85-94.

Li, Y; Yang, B.; Cui, Q. 2018. The effects of high-speed rail on air passenger transport in China, Applied Economic Letters 26(9): 745-749.

Morikawa, T.; Ben-Akiva, M.; Yamada, K. 1991. Forecasting intercity rail ridership using revealed preference and stated preference data, Transportation Research Record: Journal of the Transportation Research Board 1328: 30-35.

Schepers, J.P.; Heinen, E. 2013. How does a modal shift from short car trips to cycling affect road safety? Accident Analysis and Prevention 50: 1118-1127.

Sivakumar, T.; Okamura, T.; Yabe, T.; Nakamura, F. 2006. Survey design to grasp and compare user's attitudes on bus rapid transit in developing countries, IATSS Research 30(2): 51-58. 